\title{
Epidemiology of pseudobranchial tumours in Atlantic cod (Gadus morhua) from the North Sea and the Baltic Sea
}

\author{
B. Watermann ${ }^{1,2}$, V. Dethlefsen ${ }^{1} \&$ M. Hoppenheit ${ }^{3}$ \\ 1 Bundesforschungsanstalt für Fischerei, Institut für Küsten- und Binnenfischerei, \\ Toxikologisches Laboratorium Cuxhaven; Niedersachsenstraße, D-2190 Cuxhaven, \\ Federal Republic of Germany \\ 2 Zoologisches Institut der Universität Hamburg; Martin-Luther-King-Platz 3, \\ D-2000 Hamburg 13, Federal Republic of Germany \\ 3 Biologische Anstalt Helgoland, Laboratorium Sülldorf; Wüstland 2, \\ D-2000 Hamburg 55, Federal Republic of Germany
}

\begin{abstract}
Investigations during several cruises (1979-1981) showed that Atlantic cod with pseudobranchial tumours occurred in all areas investigated. Statistical analysis of data revealed that there was a marked prevalence of the condition in the centre of the German Bight, whereas a lower incidence of the condition was observed on the Dogger Bank, off the Dutch coast and in the western Baltic Sea. The higher prevalence of pseudobranchial tumours in the German Bight coincides with a dense population of cod and impacts of pollution.
\end{abstract}

\section{INTRODUCTION}

The occurrence of pseudobranchial tumours in Atlantic cod, Gadus morhua, was first reported by Peyron \& Thomas (1929). They reported two cases of this condition in cod from the French coast. Lange (1973) described one diseased cod caught off the western coast of Norway and one from the Oslo fjord. Lange \& Johannessen (1977) carried out investigations in the inner part of the Oslo fjord but reported no incidence. Morrison et al. (1979) found a tumour prevalence of up to $4 \%$ on the coast and continental shelf of eastern Canada. Murchelano \& Azarovitz (1979) made a fish-disease survey in the northwest Atlantic and found about $1 \%$ affected cod. Egidius et al. (1981) observed an incidence rate of $0.4-1.7 \%$ in the Barents Sea. This paper reports on the prevalence of pseudobranchial tumours in cod sampled during fish-disease surveys in the North Sea and the western Baltic Sea.

\section{MATERIAL AND METHODS}

Cod were sampled from the North Sea during cruises of RV "Anton Dohrn", in January and July 1979, January, February and June 1980 and January, May and June 1981. Sampling stations were distributed over a wide area of the German Bight includ- 
ing the dumping sites of sewage sludge and wastes from $\mathrm{TiO}_{2}$ production (Figs $1,2,4$ and 7). In addition, samples were collected in Dutch and British coastal waters and on the Dogger Bank. Samples from the western Baltic Sea were obtained in October 1980 from a cruise of RV "Solea" (Fig. 3). The data of the cruises January and May 1981 were subjected to the statistical analysis proposed by Cochran (1954). This procedure of combining the analysis of a series of $2 \times 2$ tables offers the possibility of taking length into account as an interfering variable.

The differentiation of the area under investigation into regions of higher and lower incidence rates was performed by means of the so-called stabilized p-chart (cf. Duncan, 1974, P. 402). The 1-sigma limits were chosen as the distinguishing features. If stations were outside the 1-sigma limits, they were marked by a plus and a minus sign respectively. If a station fell outside the upper 2 -sigma limit, it was provided with a second plus sign (Fig. 4). Boundary lines between the sites of higher and lower incidence were drawn regarding the signs of stations lying within the 1-sigma limits. A more detailed description of the methods of treatment of data will be given elsewhere (Dethlefsen et al., in preparation).

\section{RESULTS}

During the cruise in January 1979, pseudobranchial tumours were found at only two stations out of 35 around the sewage-sludge dumping site with two afflicted cod in the German Bight. On the cruise in July 1979, 5 tumour-bearing fish were caught at 3 stations out of 61 , in the centre and the north-western part of the German Bight. On the Dogger Banks, at one station out of 16, two afflicted fish were found. The cruise of January 1980 gave the first good impression of the epidemiological situation in wintertime. Tumour prevalence occurred on 18 stations out of 43 with 102 afflicted fish. The observed infection rates were related to the whole catches of each station. The differentiation of the area under investigation into areas of higher and lower incidence was performed by means of the p-chart. Areas in the North Sea of higher and lower prevalence are shown in Figure 1. The infection rate of the different areas is given in Table 1.

Table 1. Prevalence of pseudobranchial tumours in the North Sea (January and June 1980). Infestation rate referred to total of sampled fish

\begin{tabular}{lccc|}
\hline \multicolumn{1}{|c}{ Areas } & $\begin{array}{c}\text { No. of sampled } \\
\text { fish }\end{array}$ & $\begin{array}{c}\text { No. of diseased } \\
\text { fish }\end{array}$ & $\begin{array}{c}\text { Mean infestation } \\
\text { rate (\%) }\end{array}$ \\
\hline Janu ary 1980 & & & \\
North sea & 4430 & 82 & 1.9 \\
Area A & 5984 & 20 & 0.3 \\
Area B & 10414 & 102 & 0.9 \\
German Bight (average) & & & \\
June 1980 & & 63 & 3.1 \\
North sea & 2026 & 24 & 0.6 \\
Area A & 4013 & 87 & 1.4 \\
Area B & 6039 & & \\
German Bight & & & \\
\hline
\end{tabular}




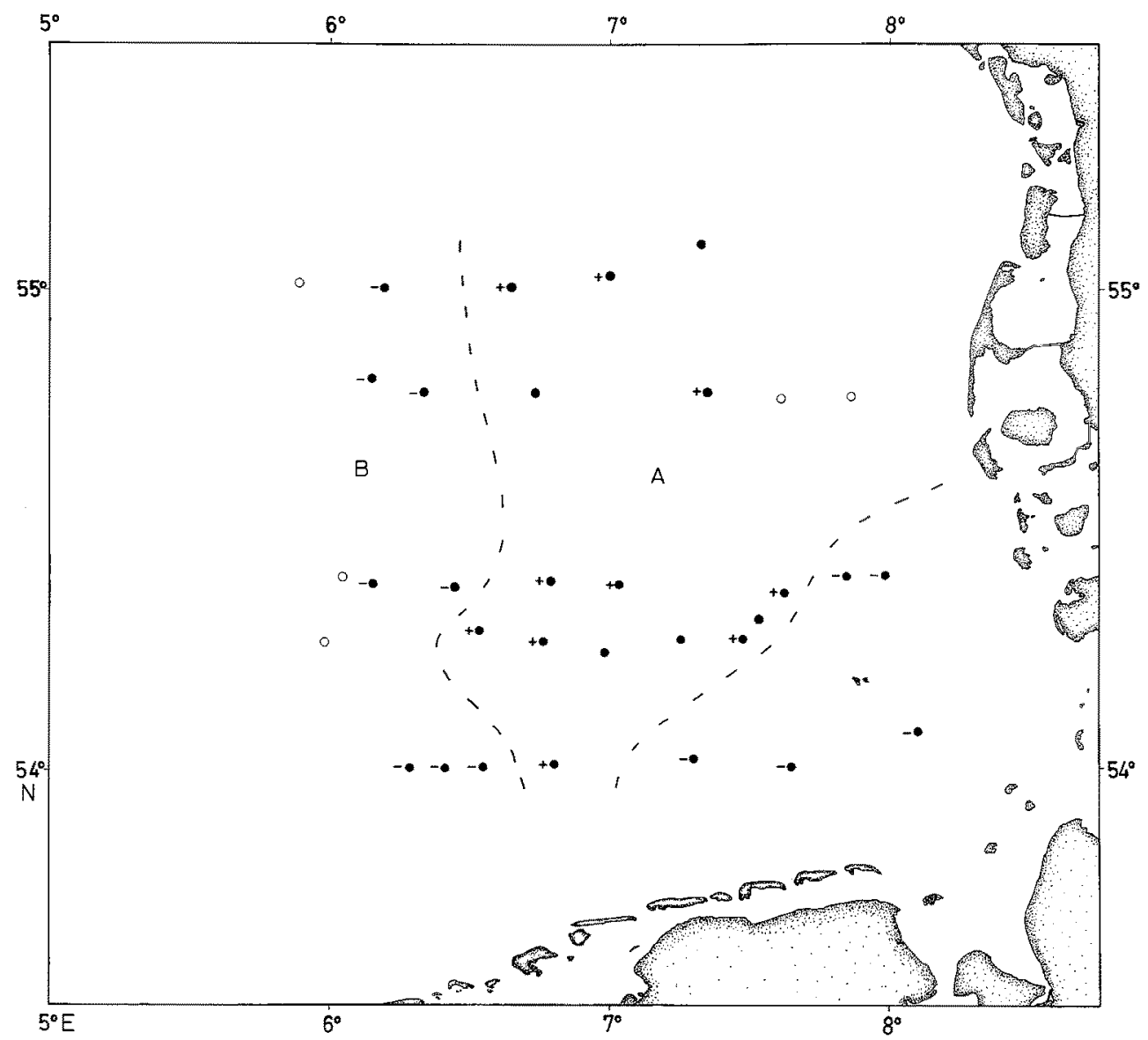

Fig. 1. Areas of higher (A) and lower (B) prevalence of pseudobranchial tumours in cod from the North Sea (January 1980). Explanation of symbols: \pm - Stations outside the 1-sigma limit $++\bullet$ stations outside the upper 2-sigma limit; stations with low number of cod (disregarded when drawing the boundary lines, but taken into account for the calculation of significance); $\bigcirc$ stations where no cod were caught; - boundary line between areas of higher and lower incidence

The cruise in February 1980 along the North Sea coast from Denmark to the Netherlands showed tumour prevalence at 3 stations out of 12 in the centre of the German Bight with 5 afflicted fish and at 3 stations out of 19 near the Dutch coast with 4 tumour-bearing cod. The cruise in June 1980 gave the first impression of the epidemiological situation in summertime with tumour prevalence at 24 stations out of 45 in the German Bight with 87 afflicted fish. Treatment of data and illustration of infection rates is given in the same way for the cruise in January 1980 (Fig. 2 and Table 1).

In January 1980 the meanlength of affected fish was between $26-40 \mathrm{~cm}$ relating to year class I and II (Lamp, pers. comm.). In June 1980 it was between 12-24 cm, relating to year class I, and $30-44 \mathrm{~cm}$ relating to year class II. 


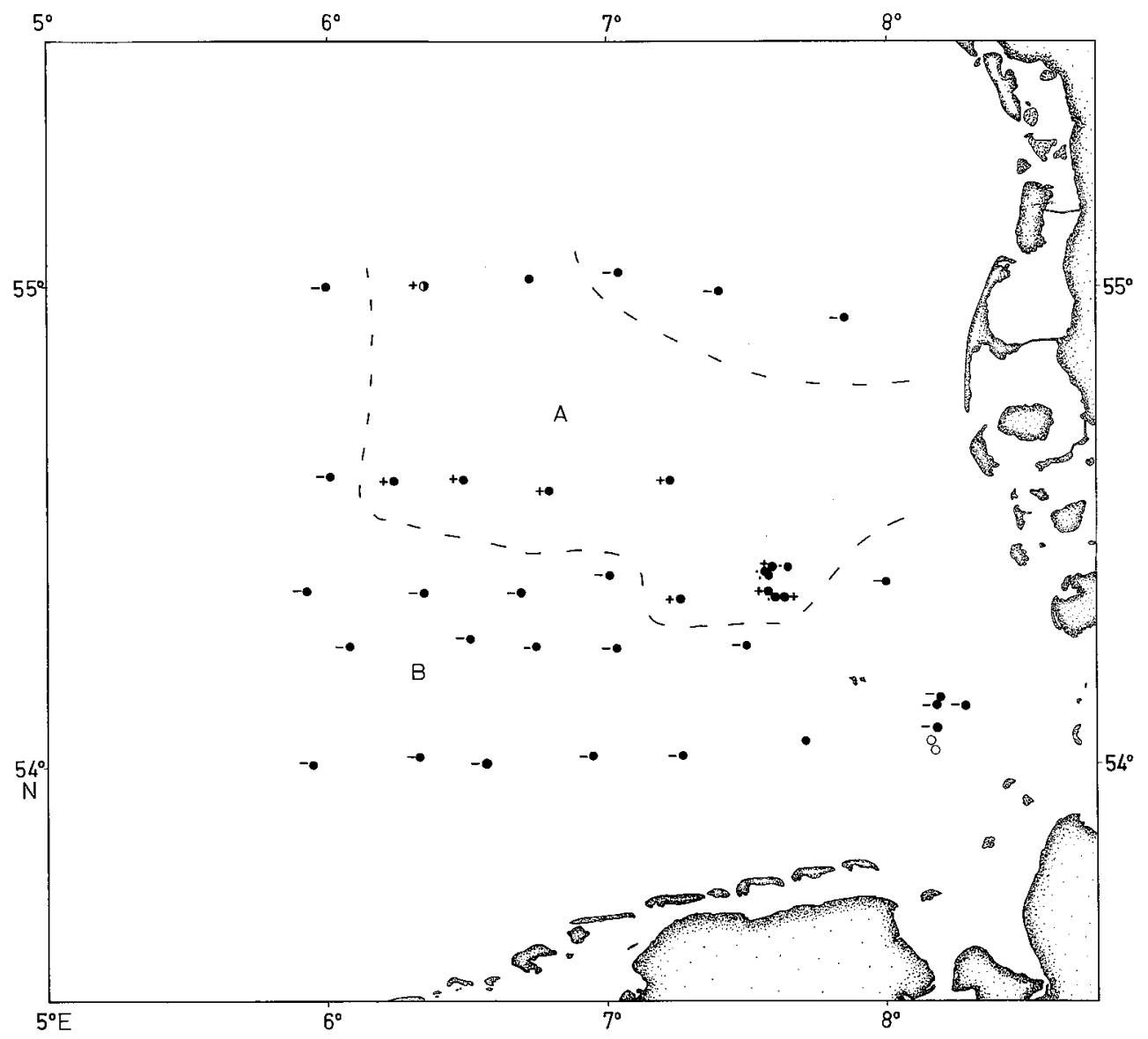

Fig. 2. Areas of higher (A) and lower (B) prevalence of pseudobranchial tumours in cod from the North Sea (June 1980). For explanation of symbols see Fig. 1

In the western Baltic Sea prevalence of pseudobranchial tumours occurred at 6 stations out of 21 with 10 afflicted cod (Fig. 3). The most affected length groups were between $18-23 \mathrm{~cm}$ and $29-31 \mathrm{~cm}$, relating to year class I (Lamp, pers. comm.). The number of sampled fish amounted to 7324 specimens with 10 diseased fish. The average infestation rate with reference to the total of sampled fish was $0.14 \%$.

In order to evaluate the epidemiological situation of this disease, taking length into account as an interfering variable, the data of the cruises January and May 1981 were subjected to statistical analyses. In January 1981, a total of 9775 specimens, 11 to $100 \mathrm{~cm}$ long, were caught. One hundred cod were found to be afflicted in the length classes of $12,13,15,17,19-39,42,43,45-47,49$ and $50 \mathrm{~cm}$. The age-length correlation was 12-30 cm for year class I, $30-54 \mathrm{~cm}$ for year class II and $47-75 \mathrm{~cm}$ for year class III (Lamp, pers. comm.) These length classes contain 8002 specimens which entered the statistical 
Table 2. Prevalence of pseudobranchial tumours in the North Sea (January and May 1981). Infestation rate referred to affected length groups

\begin{tabular}{|lccc|}
\hline Areas & $\begin{array}{c}\text { No. of sampled } \\
\text { fish }\end{array}$ & $\begin{array}{c}\text { No. of diseased } \\
\text { fish }\end{array}$ & $\begin{array}{c}\text { Mean infestation } \\
\text { rate (\%) }\end{array}$ \\
\hline January 1981 & & & \\
North sea & 2894 & 63 & 2.2 \\
Area A & 5108 & 36 & 0.7 \\
Area B & 8002 & 99 & 1.3 \\
German Bight (average) & & & 2.5 \\
May 1981 & & 107 & 4.9 \\
North sea & 4320 & 29 & 2.9 \\
Area A & 593 & 12 & 0.9 \\
Area B & 410 & 72 & 1.6 \\
Area C & 8264 & 220 & \\
Area D & 13587 & & \\
German Bight & & & \\
\hline
\end{tabular}

analysis (Table 2). One station comprising one afflicted fish was disregarded; thus 99 diseased fishes remained for the processing of data. The age-length correlation was $17-35 \mathrm{~cm}$ for year class I, $34-60 \mathrm{~cm}$ for II and $56-78 \mathrm{~cm}$ for III. The procedure of differentiation between areas with higher and lower incidence of diseased fishes yielded an area in the German Bight (Fig. 4), with a mean infestation rate of $2.2 \%$ in infested

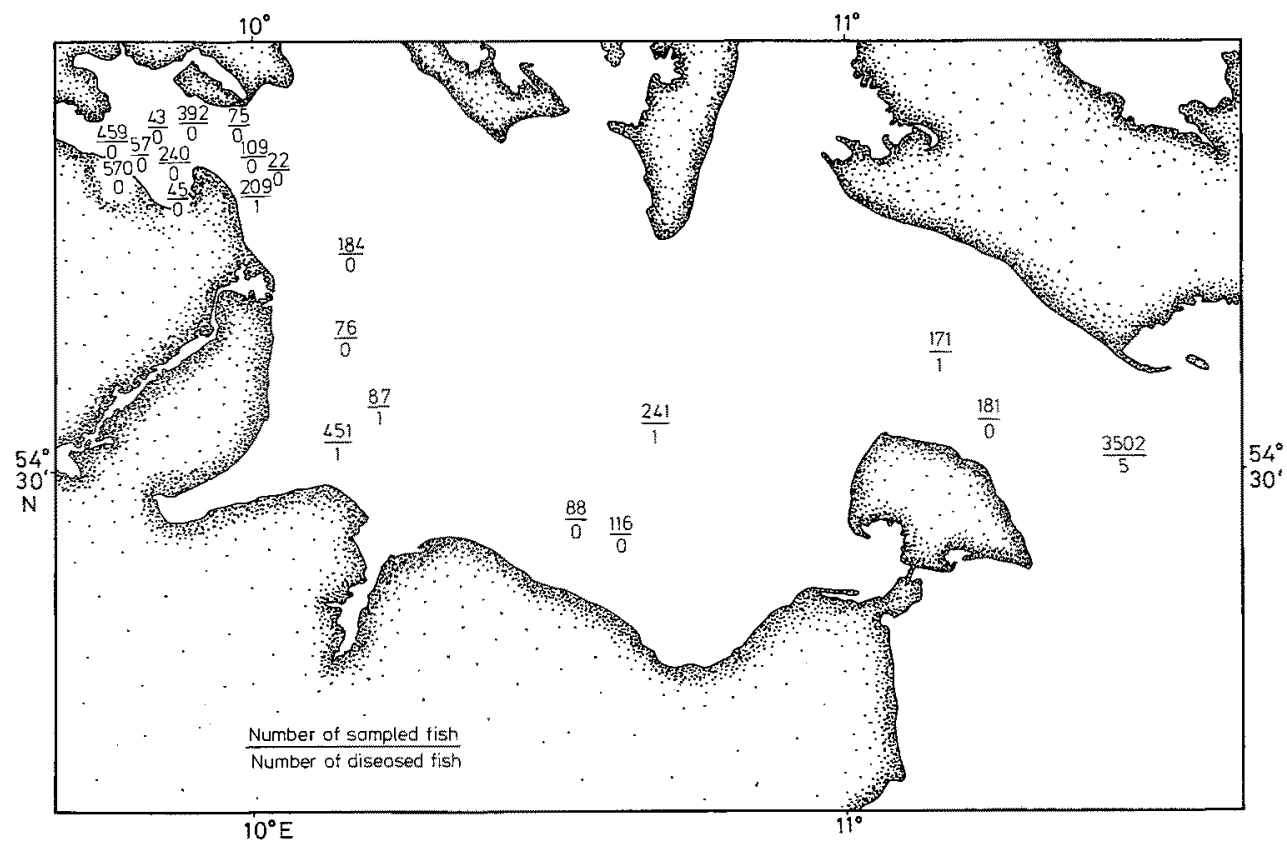

Fig. 3. Prevalence of pseudobranchial tumours in cod from the western Baltic Sea (October 1980) 


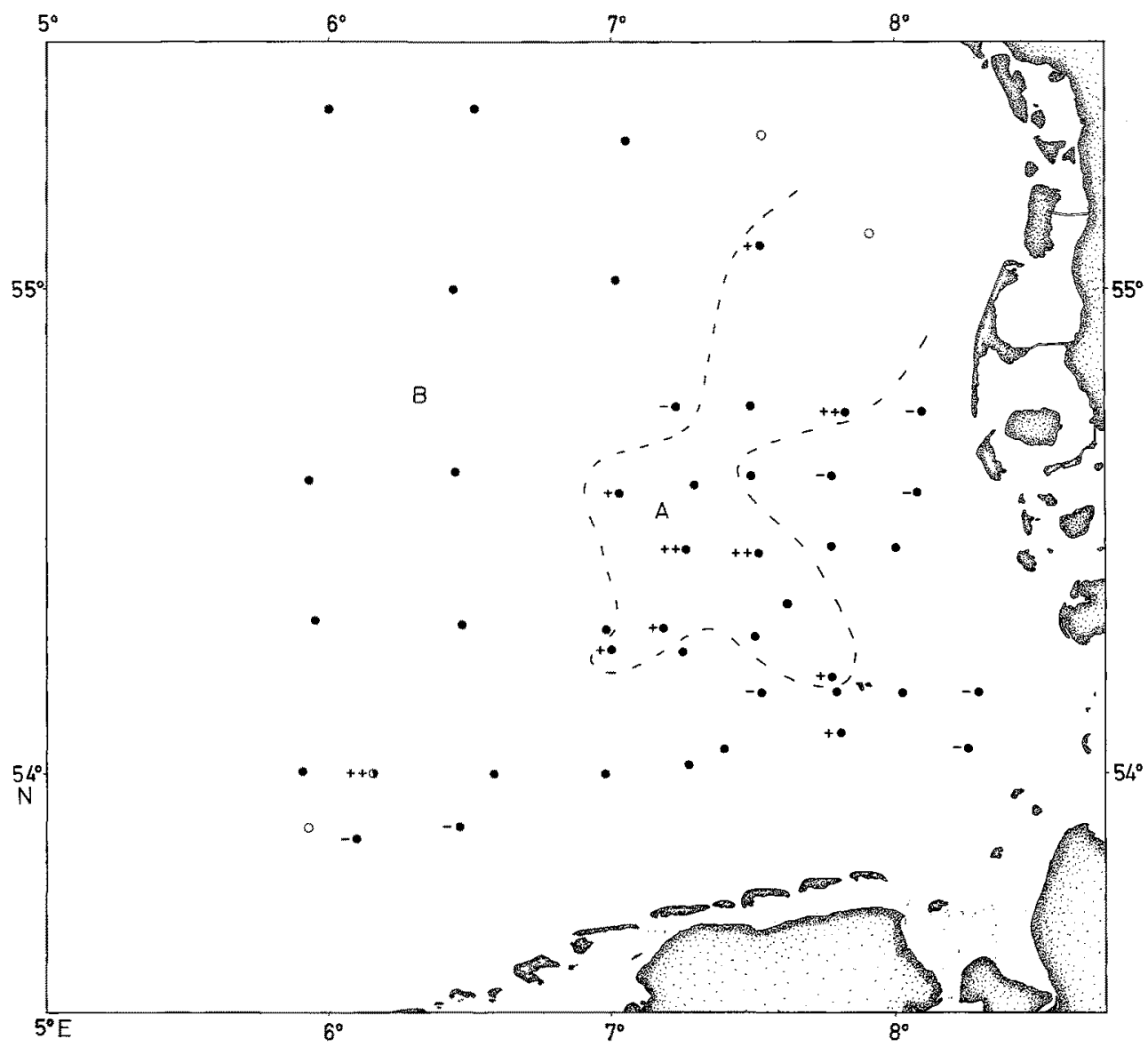

Fig. 4. Areas of higher (A) and lower (B) prevalence of pseudobranchial tumours in cod from the North Sea (January 1981). Explanation of symbols see Fig. 1

length classes. Outside this region, the mean infestation rate was $0.7 \%$. By statistical comparison a significance probability of $\alpha<5 \times 10^{-8}$ was gained for the difference. The length distribution exhibits two distinct populations (Fig.5) and an inhomogeneity between the areas under consideration. Members of the population with the smaller mean-length were relatively more frequent in the afflicted area and vice versa. Estimates of the significance probabilities for the differences in infestation yielded $\alpha<0.00025$ and $<0.00001$ for the populations with smaller and larger mean-length, respectively. Both populations can therefore be considered to contribute equally to the overall significance. Figure 6 exhibits the relative frequencies of infestation for the different length classes and areas. Despite the low number of fishes caught in length groups $12-13 \mathrm{~cm}$, the figure exhibits very high infestation rates of $16-17 \%$ in underlength specimens of year class I and II as well as considerable rates $(6 \%)$ in those of year class III. 


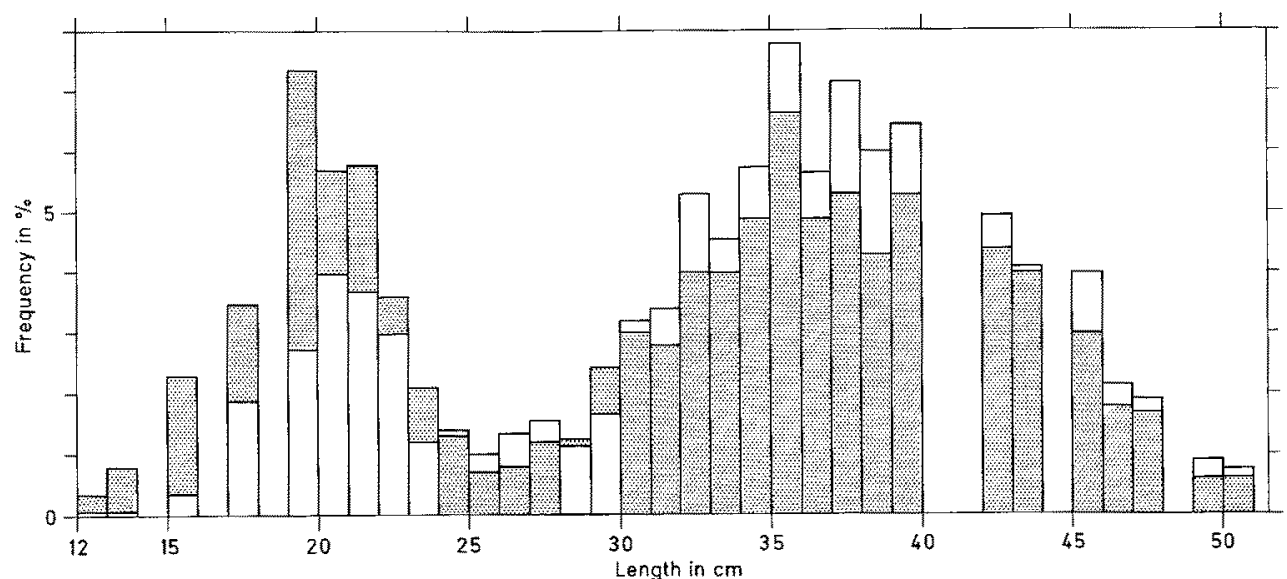

Fig. 5. Frequency distribution. Relative frequencies of cod not suffering from pseudobranchial tumours in areas $A$ (shaded) and $B$ in relation to length classes, January $1981\left(\mathrm{n}_{\mathrm{A}}=2831 ; \mathrm{n}_{\mathrm{B}}=\right.$ 5072)

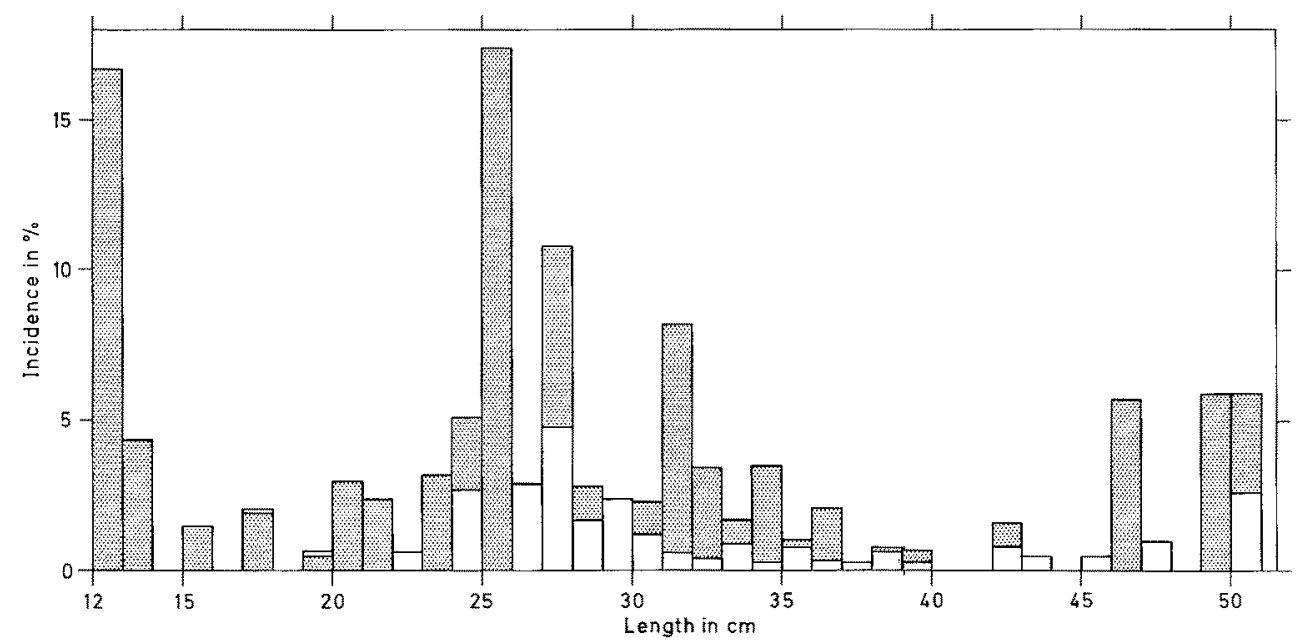

Fig. 6. Infestation rate. Relative percentages of cod in areas $A$ (shaded) and $B$ in relation to length classes found to be afflicted (January 1981) $\left(n_{A}=2894 ; n_{B}=5108\right)$

In May 1981, 14999 cod were caught in length classes 11-93 cm. The affected length classes were: $17-39,41,42,44,48$ and $49 \mathrm{~cm}$. In these length groups, 13587 specimens were caught with 220 tumour-bearing cod. This amounted to an average prevalence of $1.6 \%$ (Table 3). The statistical treatment of data yielded three areas, $\mathrm{A}, \mathrm{B}$ and $\mathrm{C}$, with significantly higher prevalence $\left(\alpha<5 \times 10^{-10},<5 \times 10^{-10}\right.$ and $\left.<5 \times 10^{-6}\right)$ in relation to the reference area D (Fig. 7). Since only low numbers of cod were caught at the stations between areas $A$ and $B$, the boundary lines in this region are uncertain. Possibly the two areas are connected. Figures 8 and 9 show the relative distribution of length classes in 


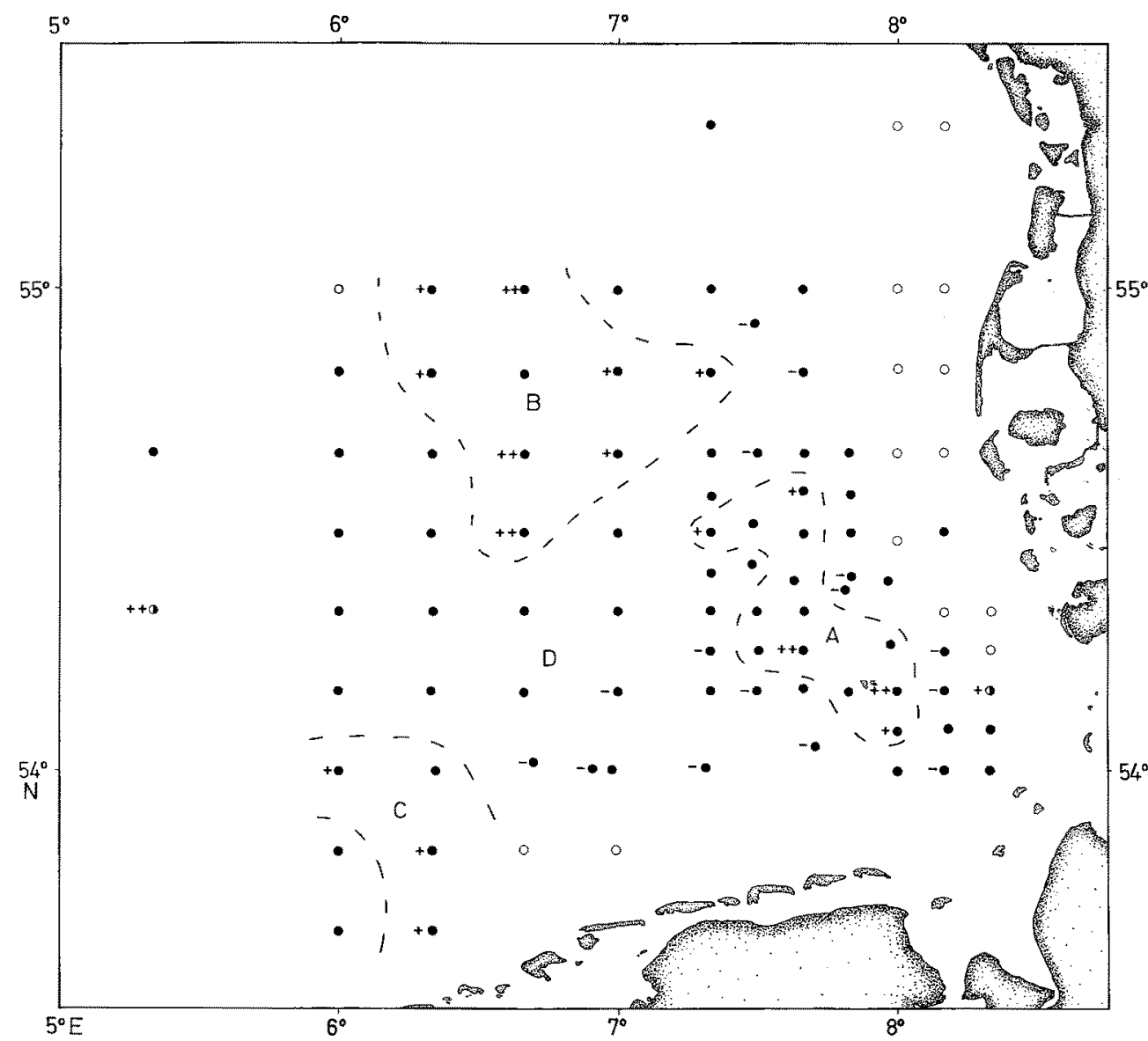

Fig. 7. Three areas $(A, B, C)$ with significantly higher prevalence of pseudobranchial tumours in cod in relation to reference area D (May 1981). Explanation of symbols see Fig. 1

the investigated areas. Specimens belonging to the older age group were more rarely caught in May and, in relation to January, both year classes were bigger in size.

The underlength fish of year class I and II showed the highest infestation rates of 10 and $16 \%$ (Fig. 10 ).

\section{DISCUSSION}

There are some old reports of exceptional cases of cod with pseudobranchial tumours from the French coast and Greenland waters (Peyron \& Thomas, 1929; see Egidius et al., 1981). Epidemiological studies were only carrid out in the Barents Sea, where a prevalence of $0.4-1.7 \%$ was found (Egidius et al., 1981), off the coast of eastern Canada with a prevalence of 1.1-3.1\% (Morrison et al., 1979) and in the northwestern Atlantic with a prevalence of $1 \%$ (Murchelano \& Azarovitz, 1979).

Fish disease surveys in Pacific areas generally revealed higher infection rates in Pacific cod (Gadus macrocephalus). Stich et al. (1976) reported an infection rate of 


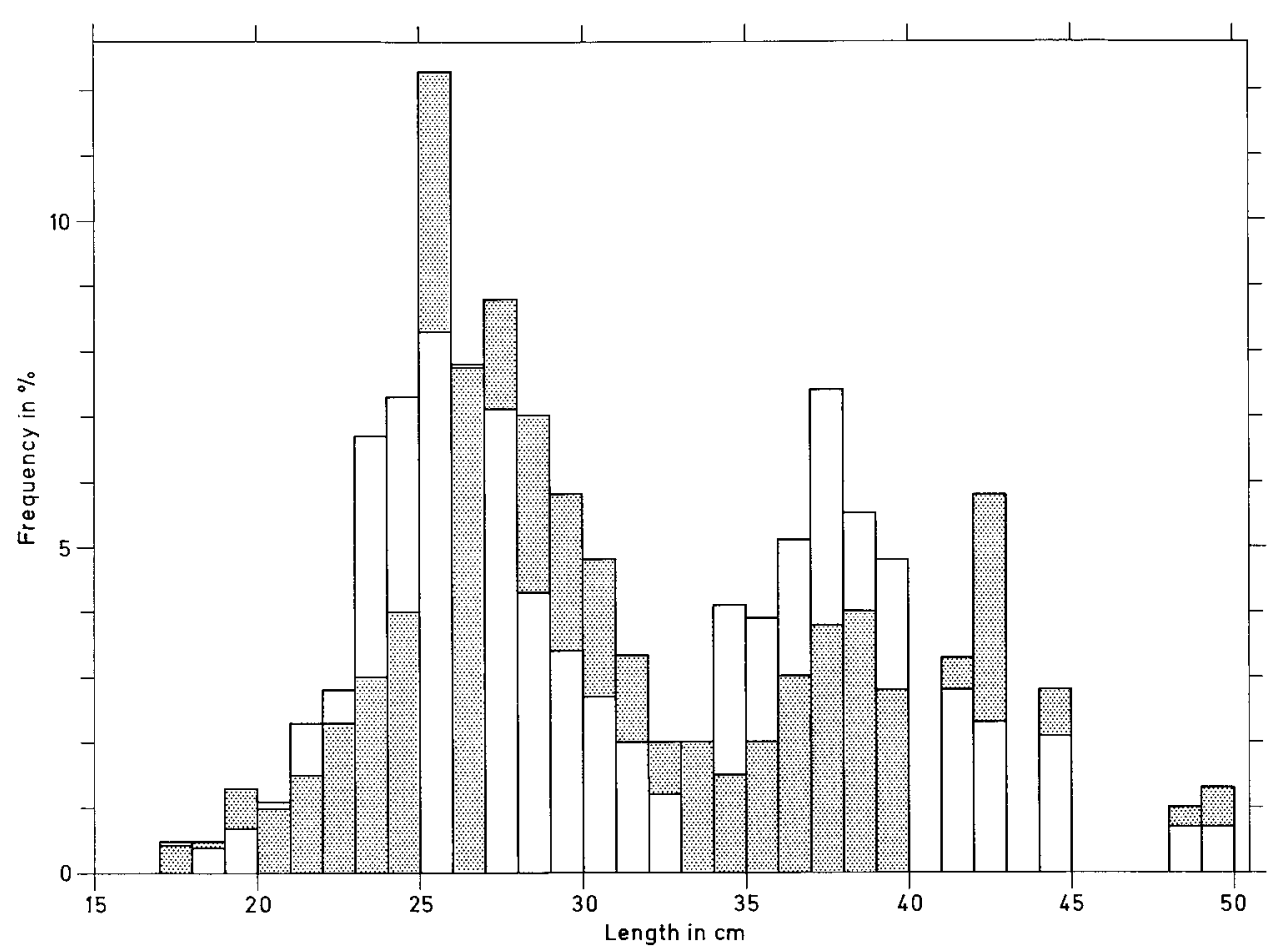

Fig. 8. Frequency distribution. Relative frequencies of cod not suffering from pseudobranchial tumours in areas $C$ (shaded) and $B$ in relation to length classes (May 1981) $\left(n_{C}=398 ; n_{D}=564\right)$

2.3-11.4\%. Wellings et al. (1977) found 7.4\% of Pacific cod in the Bering Sea with pseudobranchial tumours. McCain et al. (1979) found $1.7 \%$ of Pacific cod and $1.6 \%$ of walleye pollock (Theragra chalcogramma) with this condition in Alaskan waters. But, excepting the reports of Stich et al. (1976) and Morrison et al. (1979), the distribution patterns were irregular and showed no association with environmental contamination.

As revealed by statistical analysis the distribution patterns of pseudobranchial tumours in Atlantic cod from the North Sea (especially of the cruises in January and May 1981) showed very clearly the prevalence of the disease in coincidence with the migratory behavior and the population density. In January, the disease was restricted to the centre of the German Bight, whilst in spring the disease was spread over the whole Bight. Obviously, this corresponds with the migratory behavior of the whole stock in the German Bight (Lamp, 1973) (Figs 4, 7, 11).

The distribution pattern of pseudobranchial tumours in cod correlates positively with the population density. So it can be concluded that it is an epidemic densitydependent disease. These results are in accordance with the hypothesis that the pseudobranchial tumour is an infectious disease caused by protozoans (Watermann et al., 1982).

From investigations made during the January cruise (1981), the western extent of the higher disease incidence seems to coincide with a decrease in population density, whilst on the eastern side the incidence decreased despite a high population density (Fig. 4). 


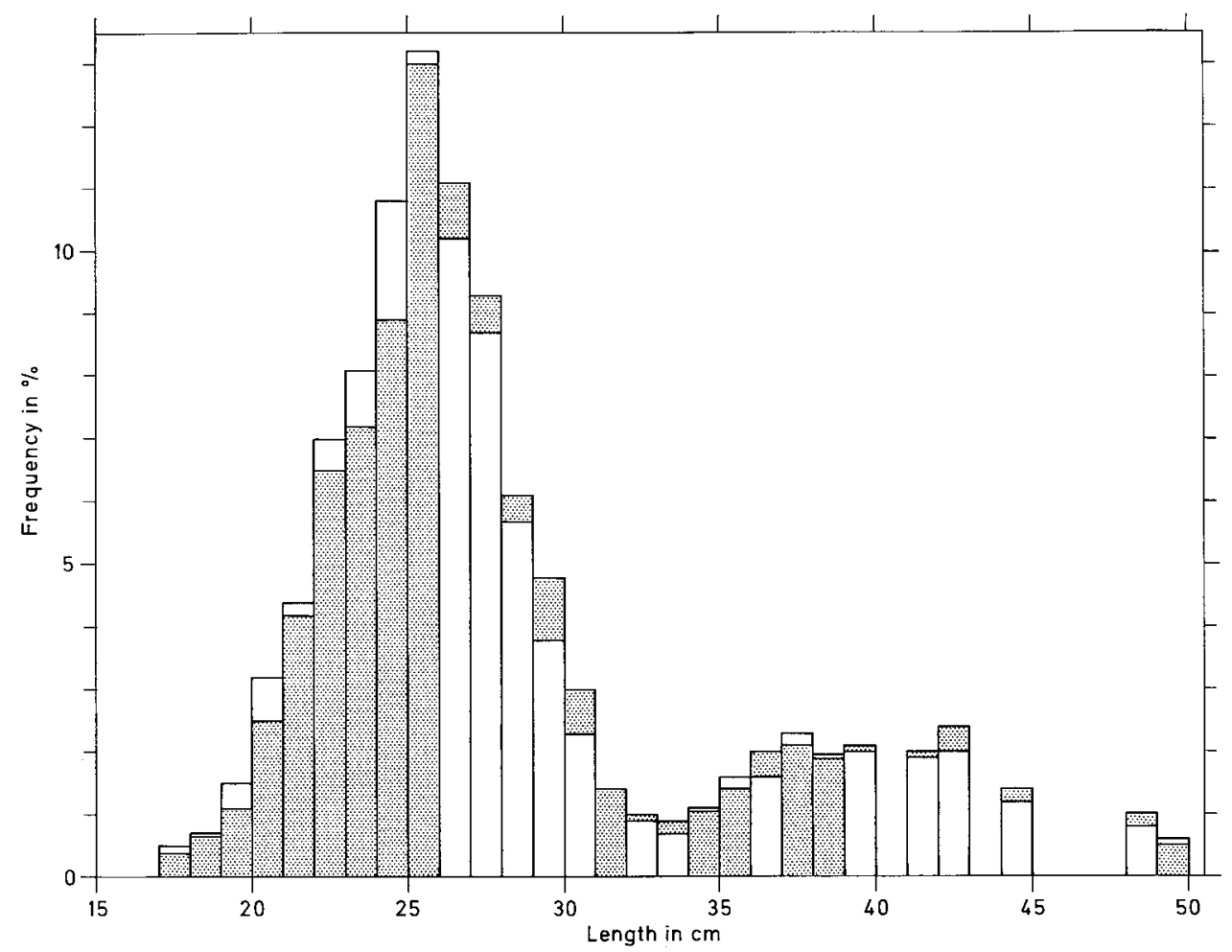

Fig. 9. Frequency distribution. Relative frequencies of cod not suffering from pseudobranchial tumours in areas $A$ (shaded) and $D$ in relation to length classes (May 1981) $\left(n_{A}=4213 ; n_{D}=8192\right.$ )

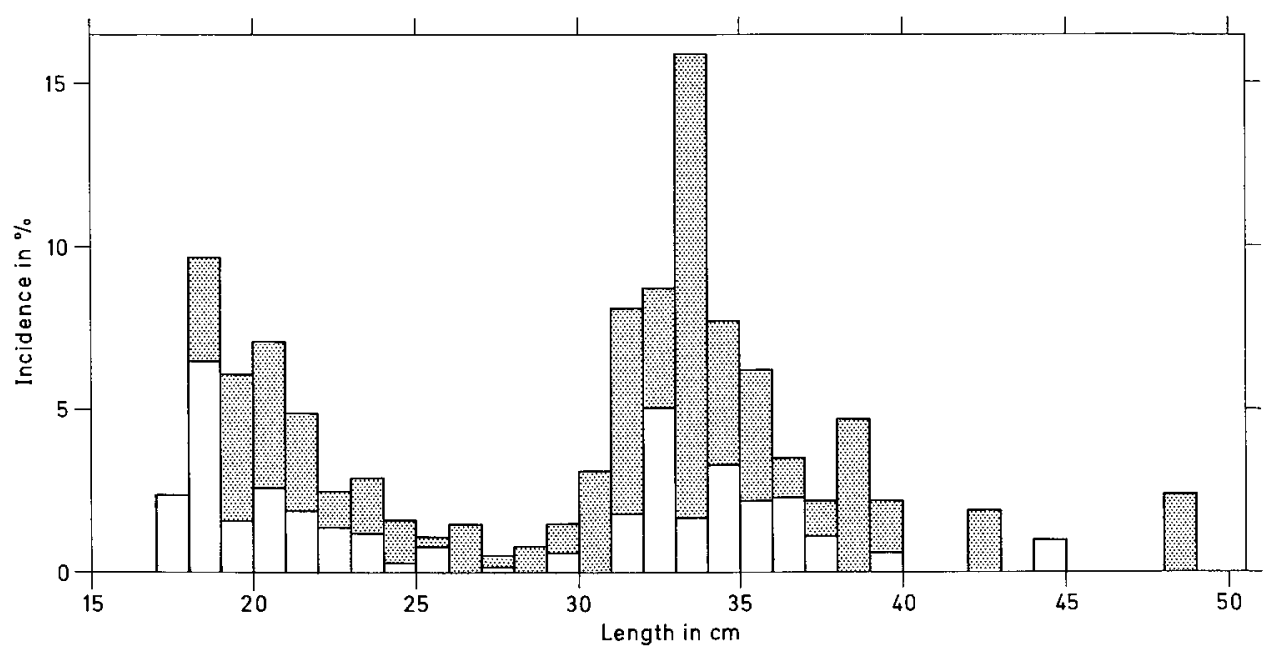

Fig. 10. Infestation rate. Relative percentages of cod in areas $A$ (shaded) and $D$ in relation to length classes found to be afflicted (May 1981) $\left(n_{A}=4320 ; n_{D}=8264\right)$ 


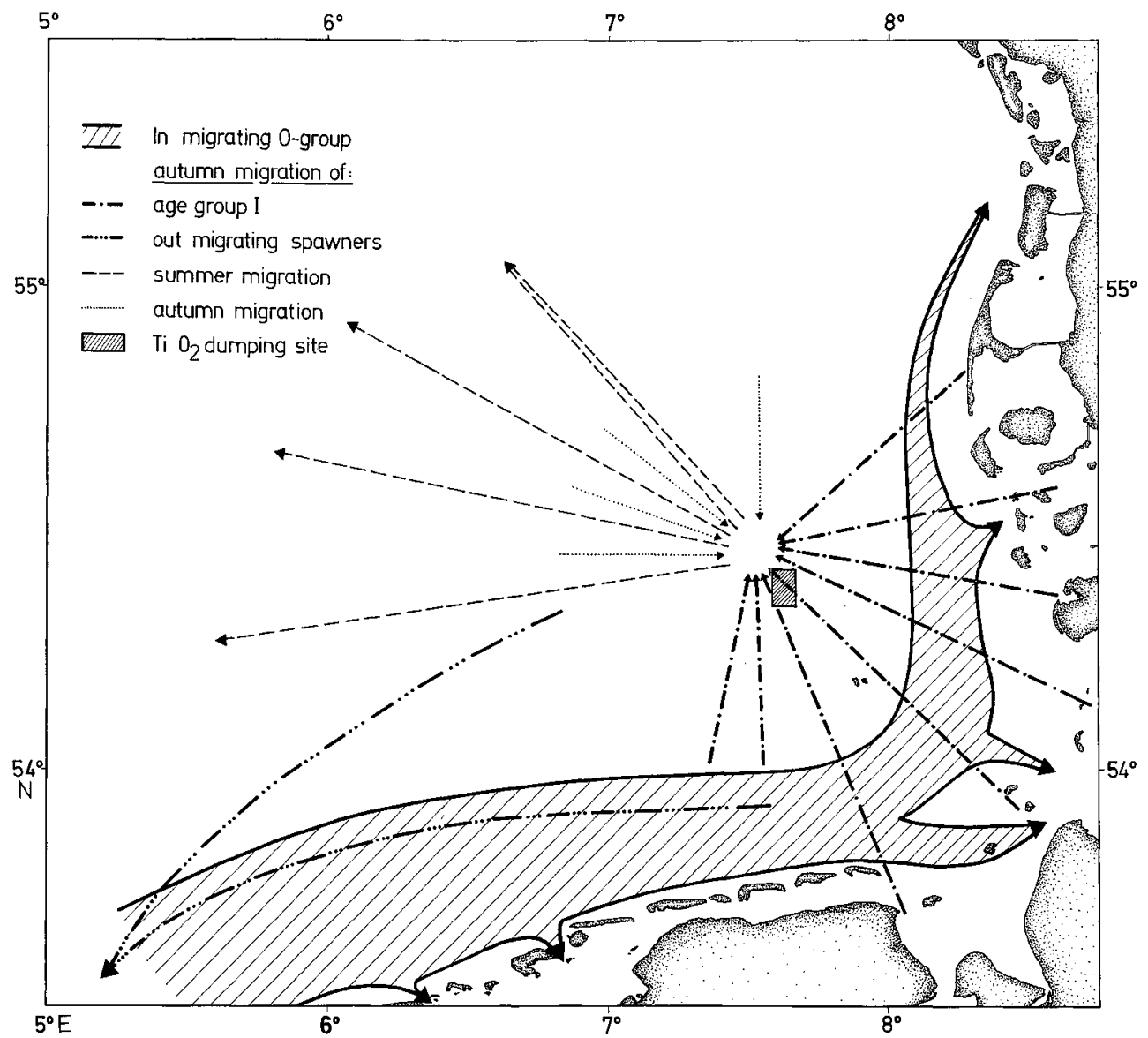

Fig. 11. Migratory behavior of cod in the German Bight (modified after Lamp, 1973)

Apparently, the decrease was not due to low salinity levels near the coast $(29 \%$ in the respective area) because affected cod were also found in the Baltic Sea (in areas of 10-20\% salinity). This situation indicates that, besides population density, some other factors which may favour the outbreak of the disease should be taken into account.

Infection was most frequently seen in under-length fish of each year class. These observations are in accordance with some reports on tumour-bearing cod from the Atlantic as well as Pacific Ocean. Stich et al. (1976) and Morrison et al. (1979) found that tumour prevalence, highest in fish of small size, decreased with increasing length. The first authors suggested that the presence of tumours might inhibit growth and maturation. McCain et al. (1979) found tumour-bearing walleye pollock with a depressed growth rate: at the age of 3 to 5 years they were shorter by $15 \%$ than their cohorts. With regard to the infestation in fish of year class $I_{1}$ it can be assumed that all these cases are fresh incidences for the respective year, which means that these specimens are newly diseased fish. For the infestation in year class II the situation is more difficult. There are some indications that these are fresh cases of disease, too. Very small lesions could also 
be found in this year class and the infection rate is the same or even higher than in year class I. On the other hand, tumour volume increases with fish length up to year class I, but the tumours are of varying volume so that $50 \%$ of these fish have much smaller tumours than their cohorts (Dorsch, 1981). However, estimations of pseudobranchial tumour-induced mortality are very difficult to make, because the aggregating cod of year class I and II are heavily reduced by fishing intensity (up to $60 \%$; Lamp, 1973). Furthermore, the natural mortality in prerecruit juveniles is generally very high (Munro et al., 1980).

Taking into consideration the factors which favour the outbreak of the disease, population density seems to play a dominant role. Anderson (1979) suggested that the density-dependent nature of epidemics is probably associated with the increased pathogenicity of many parasitic organisms within poorly nourished or stressed hosts rather than increased transmission efficiency at high host densities. As shown by the epidemiological data, the starting point of the disease appears to be located in that area where the cod population assembles in wintertime. When considering stress factors which may favour the outbreak of the investigated disease, it should be pointed out that the area of significantly high prevalence includes a $\mathrm{TiO}_{2}$ dumping site where annually 750.000 tons of acid iron waste are dumped (Fig. 11). Therefore, these wastes which are known to be harmful to fish should not be dumped.

Acknowledgements. Special thanks are given to Dr. H. Rosenthal for releasing data of the May 1981 cruise. We also thank Mrs. R. Kleinfeld for the laborious statistical treatment of the data and the drawings. For the latter, additional thanks are due to Mrs. M. Hänel. We are indebted, too, to Dr. D. Bucke for the critical review of the manuscript and Mrs. H. Rennert for technical assistance.

\section{LITERATURE CITED}

Anderson, R. M., 1979. The influence of parasitic infection on the dynamics of host population growth. In: Population dynamics. Ed. by R. M. Anderson, B. D. Turner \& L. R. Taylor. Blackwell, Oxford, 245-281.

Cochran, W. G., 1954. Some methods for strengthening the common $\chi^{2}$ tests. - Biometrics 10 , $417-451$.

Dorsch, K., 1981. Pseudobranchialtumore beim Kabeljau der Nordsee (Gadus morhua). - Dipl.-Arb., Univ. Hamburg, $65 \mathrm{pp}$.

Duncan, A. J., 1974. Quality control and industrial statistics. - Irwin, Homewood, Ill. 1047 pp.

Egidius, E. C., Johannessen, J. V. \& Lange, E., 1981. Pseudobranchial tumours in Atlantic cod, Gadus morhua L., from the Barents Sea. - J. Fish Dis. 4, 527-532.

Lamp, F., 1973. Das Wanderverhalten des Kabeljau in der Deutschen Bucht. - Arch. FischWiss. 24, 155-169.

Lange, E., 1973. Carcinoid-like tumours in the pseudobranch of Gadus morhua. - Comp. Biochem. Physiol. 45A, 477-481.

Lange, E. \& Johannessen, J. V., 1977. Histochemical and ultrastructural studies of chemodectomalike tumours in the cod (Gadus morhua). - Lab. Invest. 37, 96.

McCain, B. B., Gronlund, W. D., Myers, M. S. \& Wellings, S. R., 1979. Tumours and microbial diseases of marine fishes in Alaskan waters. - J. Fish Dis. 2, 111-130.

Morrison, C. M., Appy, R. G., Shum, G., Annand, C. \& Odense, P., 1979. Histology and the incidence of pseudobranch tumours in Atlantic cod (Gadus morhua) in Halifax Harbour. - C. M. - ICES, E 31 .

Munro, A. S., McVicar, A. H. \& Jones, R., 1980. The epidemiology of infectious disease in commercially important wild marine fish. In: Special Meeting on Diseases of Commercially Important Marine Fish and Shellfish. ICES, Copenhagen. 
Murchelano, R. \& Azarovitz, T., 1979. Fish disease surveys in the Western North Atlantic. - C. M. ICES, E 24.

Peyron, A. \& Thomas, L., 1929. Contribution à l'étude des tumeurs du revêtement branchial chez les poissons. - Bull. Ass. fr. Etude Cancer 18, 825-827.

Stich, H. F., Acton, A. B. \& Forrester, C. R., 1976. Fish tumours and sublethal effects of pollutants. - J. Fish. Res. Bd Can. 33, 1993-2001.

Watermann, B. \& Dethlefsen, V., 1982. Histology of pseudobranchial tumours in Atlantic cod (Cadus morhua) from the North Sea and the Baltic. - Helgoländer Meeresunters. 35, 231-242.

Wellings, S. R., Alpers, C. E., McCain, B. B. \& Myes, M. S., 1977. Fish disease in the Bering Sea. Ann. N. Y. Acad. Sci, 298, 290-304. 